DOI 10.37882/2223-2982.2020.04-2.30

\title{
КОММУНИКАТИВНО-ПРАГМАТИЧЕСКИЕ СПОСОБЫ И СРЕДСТВА РЕПРЕЗЕНТАЦИИ РЕЧЕВОГО АКТА ЗАПРЕТА
}

\section{COMMUNICATIVE-PRAGMATIC METHODS AND MEANS OF REPRESENTING THE SPEECH ACT OF PROHIBITION}

\section{O. Rossolova}

Summary: This paper presents a study of pragmatic ways of representing the prohibition in Russian speech, revealing pragmatic characteristics that influence the formation, development and completion of the communicative situation of prohibition. The principal ways of expressing prohibition in Russian speech are identified, lexical and grammatical means of expressing prohibition are presented, typical structural patterns of prohibitive statements are considered. The socio-psychological nature of the communicative situation of prohibition is examined. The theoretical propositions of the study are confirmed by a thorough analysis of linguistic material containing speech acts of prohibition.

Keywords: pragmatics, communicative situation, persuasive speech act, speech act of prohibition, direct prohibition, indirect prohibition
Россолова Оксана Анатольевна

К.филол.н., дочент, ФГБОУ ВО «Камчатский государственный университет имени Витуса Беринга», г. Петропавловск-Камчатский oksross@mail.ru

Аннотация: В данной работе представлено исследование прагматических способов репрезентации запрета в русской речи, выявлены прагматические признаки, влияющие на становление, развитие и завершение коммуникативной ситуации запрещения. Выявлены основные способы выражения запрета в русской речи, представлены лексические и грамматические средства выражения запрета, рассмотрены типичные структурные модели высказываний-запретов. Рассматривается социопсихологическая природа коммуникативной ситуации запрета. Теоретические положения исследования подтверждаются тщательным анализом языкового материала, содержащего речевые акты запрета.

Практическая значимость работы заключается в том, что результаты данного исследования могут найти применение в вузовской практике преподавания лингвопрагматических дисциплин, а также в цикле дискурсивных дисциплин.

Ключевые слова: прагматика, коммуникативная ситуация, побудительный речевой акт, речевой акт запрета, прямой запрет, косвенный запрет.

ния, разработки и структурирования коммуникативнопрагматических характеристик коммуникативной ситуации запрета, выявления основных сценариев ситуации запрещения. Объектом исследования является коммуникативная ситуация запрета. Предмет исследования коммуникативно-прагматические и языковые средства реализации семантики запрета в речевой деятельности.

Цель данного исследования - изучение и описание прагматических способов репрезентации запрета в коммуникативном взаимодействии, выявление коммуникативно-прагматических особенностей выражения прямого и косвенного запрета; построение целостной системы описания речевого акта запрета.

Методы исследования:

1. метод лингвистического наблюдения и описания;

2. сравнительно-сопоставительный метод;

3. описательный метод;

4. метод компонентного контекстуального анализа.

Классификации побудительных речевых актов опираются на различные признаки, связанные с языковой личностью, например, на социально-коммуникативный статус собеседников, облигаторность выполнения действия, на сферу общения и др. $[1 ; 2 ; 5 ; 6 ; 9]$. В рамках теории речевых актов исследователи приводят разные 
классификации речевых актов (далее РА - О.А.Р.), но во всех классификациях присутствует РА, цель которого побудить собеседника к началу или окончанию какоголибо действия. Д. Вундерлих выделяет группу речевых актов директивов, в которую входят просьбы, требования, указания, приказы, распоряжения, инструкции, установление норм. Директивы открывают последовательность действий. Г.Г. Почепцов в рамках лингвистической теории предложения разделяет директивы на инъюктивы (предложение-приказ) и реквестивы (предложение-просьба). Дж. Н. Лич, ориентируясь на риторический принцип вежливости, выделяет конкурирующую функцию локутивных актов, к которой относит распоряжение, просьбу, приказ, мольбу [7, 149 - 171].

Классификации побудительных речевых актов (далее ПРА - О.А.Р.) опираются на разные принципы, которые позволяют определить специфику ПРА относительно других РА и выделить различные РА внутри ПРА (совет, инструкция, просьба и др.) Основные аспекты, на которые опираются классификации ПРА: семантический аспект состоит в выявлении отнесенности к действительности побудительных высказываний; синтаксический аспект заключается в анализе средств выражения побуждения на синтаксическом уровне; коммуникативно-прагматический аспект направлен на учет факторов социолингвистического и социопрагматического характера. Трудность классифицирования ПРА заключается в том, что выделение речевых актов внутри ПРА во многом определяется интуицией исследователя, поэтому количество и характер абсорбируемых речевых актов у различных исследователей варьируется в значительных пределах. Также трудность заключается в том, что некоторые речевые акты (пожелание, угроза, намек) не являются собственно побудительными, хотя и содержат императив, т.к. основная форма русского императива способна участвовать в реализации РА, которые не являются только побудительными. Большинство исследователей (Е.И. Беляева, Ц. Саранцацрал, Е.А. Филатова, Е.А. Формановская) выделяют такой класс ПРА как запрет или запрещение.

Классификация РА Е.И. Беляевой основана на трех признаках: обязательность выполнения действия, приоритет адресанта и выгодность действия для адресанта. На основе этих признаков выделяются следующие группы ПРА:

1. прескриптивы, в которые включаются распоряжение, приказ, запрещение, разрешение, предписание, инструкция, заказ;

2. суггестивы, в которые включаются предложение, совет и предупреждение;

3. реквестивы, в которые включаются просьба, приглашение и мольба.

Прагматическими признаками ПРА являются побу- дительные мотивы, желательность / нежелательность действия, участие / неучастие в выполнении действия, содержание действия, характер источника побуждения, сфера коммуникации [3, 18 - 20].

Н.И. Формановская, опираясь на вышеизложенную классификацию, выделяет следующие виды ПРА, основываясь на социальном статусе говорящих и бенефактивности действия:

1. инъюнктивы, или прескриптивные РА. К ним относятся требование, приказ, распоряжение, команда, предписание, запрещение, наставление, принуждение, разрешение. Данные РА объединены по следующим признакам: приоритет говорящего, его социальный статус выше, действие облигаторно для адресата, т.к. невыполнение действия может вызвать карательные меры со стороны адресанта;

2. реквестивы, к ним относятся мольба, заклинание, просьба. Действие выгодно говорящему, адресат обладает приоритетом, действие не обязательно для адресата;

3. адвисивы, к ним принадлежат инструкция, совет, рекомендация, предложение, рецепт, приглашение. Каузируемое действие выгодно и желательно для адресата $[9,92]$.

Для выделения речевого акта запрета как самостоятельного типа побуждения необходимо обратить внимание на такие критерии, как:

1. обладание специфическими (семантическими, функциональными, прагматическими) свойствами, отличающими его от других семантических типов побуждения;

2. наличие собственного набора языковых средств выражения значения.

Важной составляющей для языковых средств в парадигме запрещения является семантика запрета - «типовое значение, присущее конструкциям, содержащим побуждение собеседника к неосуществлению, прекращению или видоизменению действия, названного говорящим» $[4,26]$. Комплексный анализ РА негативной реакции, к которым можно отнести РА запрета позволяет построить классификацию РА запрета с учетом характера инициальной реплики или стимульного действия, послуживших причиной данного РА:

1. запрещение начатого собеседником речевого действия;

2. запрещение планируемого собеседником действия;

3. запрещение начатого собеседником невербального действия.

Анализ существующих классификаций показал, что запрещение является самостоятельным семантическим 
типом побуждения, который обладает общими признаками побуждения: наличием инициатора побуждения и исполнителя побуждения, спецификой причин и целей побуждения, позитивного или негативного результата побуждения. И специфическими признаками, отличающими его от других семантических типов побуждения: коммуникативной целью, средствами и способами выражения типового значения, характером воздействия на адресата.

Центральными составляющими коммуникативной ситуации запрета является:

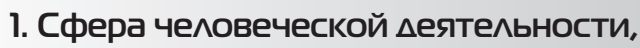 в которой происходит обшение.}

Максимально часто речевой акт запрета реализуются в деловой (производственной, административной, учебной) и бытовой (семейной, дружеской) сферах общения, которые обусловливают выбор языковых средств для реализации интенции запрещения: одни средства предпочтительно применяются в деловой сфере общения (например, глаголы и глагольные формы лексико-семантической группы запрещения: «запрещается / запрещено / воспрещается / воспрещено»; при этом применение конкретных конструкций ведет к тому, что коммуникация обретает признаки ритуала), иные - в бытовой сфере (лексема со значением запрещения «нельзя», особенно в ситуации старший - младший), третьи считаются нейтральными и имеют все шансы быть использованными в любой сфере (инфинитив и императив с оператором отрицания «не»).

Как пример функционирования запрета в официальной сфере можно использовать выдержку из правил поведения в Московском Метрополитене:

2.11. На территории метрополитена запрещается:

2.11.1. Распивать пиво и напитки, изготавливаемые на его основе, алкогольную и спиртосодержащую продукцию, потреблять наркотические средства или психотропные вещества, появляться в состоянии опьянения.

\subsubsection{Kурumb.}

2.11.3. Создавать ситуации, мешающие движению пассажиропотока - в данном случае коммуникация массовая, т.к. рассчитана на восприятие различными людьми, объединенными лишь местом. 3anpem выражен прямо и реализуется с помощью использования лексемы «запрещается» и инфинитива.

Функционирование запрета в бытовом общении:

Два детские голоса (Степан Аркадьич узнал голоса Гриши, меньшого мальчика, и Тани, старшей девочки) послышались за дверьми. Они что-то везли и уронили.
- Я говорила, что на крышу нельзя сажать пассажиров, - кричала по-английски девочка, - вот подбирай! (Л. Толстой) - в данной коммуникативной ситуации межличностная коммуникация происходит между коммуникантами, статусы которых не равны, инициатор запрета - старшая девочка, имеющая более высокий статус по возрасту, по жизненному и социальному опыту, адресат запрета - ее младший брат.

\section{2. ААресант запрешения, его мотив и шель}

Адресант и адресат запрещения в при официальном общении находятся в иерархических отношениях «начальник - подчиненный», в неофициальной - «старший - младший»; сюда же можно отнести и оппозицию: имеющий моральное право запрещать - не имеющий такого права.

Адресант запрещения в любой ситуации имеет характерную черту - повторяющуюся особенность вербального поведения - склонность к регулятивному типу действий. Речевое действие запрета он выполняет в надежде на соответствующий эффект, который приведет к восприятию и пониманию адресатом.

Адресант запрещения наделен правом препятствовать адресату в осуществлении некоторого действия, если это действие, по его мнению, не укладывается в рамки норм, принятых в данной социальной среде; говорящий располагает властью распоряжаться и корректировать действия собеседника, если они противоречат планам говорящего.

Речевое поведение адресанта направлено на успешную реализацию контакта как в условиях межличностной, так и в условиях массовой коммуникации.

К Остапу быстро вернулись вся его решительность ихладнокровие.

- Ну, вы, дамский любимеи, стойте здесь и никуда не выходите. Я через пять минут приду. А вы тут смоmpume, кто и что. Чтоб ни один стул не ушел (И. Ильф, Е. Петров) - в данном случае адресант (Остап) находится на позиции лидера, и, следовательно, обладает правом запрещать Воробьянинову отлучаться.

\section{3. Мотив запрешения - причина, побужАаюшая адресанта к запрешению.}

Мотивами запрещения служат физические, психические или вербальные действия собеседника, которые, по мнению говорящего, недопустимы в целом или недопустимы в определенной ситуации. Цель запрета заключается в попытке адресанта прекратить, предотвратить, приостановить или изменить планируемое или совер- 
шаемое собеседником действие, при этом адресант обладает полномочиями для осуществления запрета.

Увидев в своей комнате человека, уносящего опечатанный стул, Авессалом Владимирович взмахнул только что выглаженными у портного брюками, подпрыгнул и заклекотал:

- Вы с ума сошли! Я протестую! Вы не имеете права! Есть же, наконеи, закон! Хотя дуракам он и не писан, но вам, может быть, понаслышке известно, что мебель может стоять еще две недели!.. Я пожалуюсь прокурору!.. Я уплачу, наконец! (И. Ильф, Е. Петров) - в данном контексте адресант выражает протест и запрет в ответ на действия адресата, который уносит из комнаты стул, при этом адресант ссылается на закон, согласно которому возможна реализация запрета на действия: стул должен остаться у него.

\section{4. Молель амресата}

Модель адресата - любая речевая ситуация рассчитана на определенную модель адресата: коммуникативный портрет адресата будет определять развитие ситуации общения в том или ином направлении. Учитывая специфику речевых действий запрета (запрещение непосредственно или опосредованно адресовано, но адресат запрещения в любом случае должен получить переданную ему информацию сразу или спустя какое-то время) в коммуникативной ситуации запрещения невозможно выделение виртуального адресата.

В зависимости от цели говорящего и характера ответных действий адресата коммуникация может иметь успешный или неуспешный исход. Успешный исход реализуется в случае понимания и принятия адресатом цели адресанта, неуспешный - в случае неприятия. Успешность воздействия высказывания запрета на адресата определятся субъективными экстралингвистическими факторами:

- коммуникативной ситуацией, которая должна быть благоприятной для репрезентации запрета (то есть РА запрета должен быть уместен в данной речевой ситуации);

- коммуникативной заинтересованностью инициатора взаимодействия (то есть он должен быть небезразличен к качествам и поступкам того, кому адресован запрет);

- наличием определенных личностных качеств инициатора запрета (тактичности, искренности, настойчивости, убедительности и авторитетности).

Анализ причин негативной реакции на высказывания запрета показал, что негативная реакция может быть обусловлена такими причинами, как неуверенность адре- сата в искренности адресанта, антипатия адресата к говорящему, неуместность высказывания запрета в конкретной ситуации.

Семантика запрета может выражаться эксплицитно и имплицитно. Прямой запрет выражается языковыми средствами с определенной семантикой запрещения, например, императивом с частицей «не», отрицательными наречиями в сочетании с глаголом и т.д. По параметру расчлененности прямой запрет можно разделить на подвиды.

\section{1. дискретно-недискретный запрет, например:}

- Не ори! - выкрикнул Валет (М. Шолохов) - в данном случае идея побуждения мыслится слитно с идеей действия (недискретно), а идея отрицания - отдельно, противопоставляясь слитному отражению побуждения и действия (дискретно).

2. дискретный запрет - идея запрета и идея запрещаемого действия всегда представлены дискретно, но степень дискретности может различаться. Возможно расчленение содержания мысли на два компонента, когда противопоставляются идея запрета и понятие о запрещаемом действии:

- Я должен во что бы то ни стало сегодня уехать...

- Плюнь, сейчас нельзя уезжать... (А. Толстой) - в данном РА в одном компоненте мыслится запрет (в слове категории состояния «нельзя»), а в другом - запрещаемое действие (в слове «уезжать»).

Возможна и более высокая степень расчлененности содержания в случае, когда идея запрета, в свою очередь, разделяется на идею отрицания и идею побуждения или разрешения.

- ...Я никому не позволю шутить, издеваться надо мною и, черт подери, когда я взбешен, никому не советую близко подходить ко мне... (А. Чехов) - в рассматриваемом случае наблюдается расчленение содержания на три компонента: идею отрицания, сосредоточенную в частице «не», идею разрешения, выраженную в словах «позволю», «советую», идею действия, сконцентрированную в инфинитивах «шутить», «издеваться», «подходить».

Косвенный (имплицитный) запрет оказывается предпочтительным при желании выразить идею запрета в несколько смягченной, некатегоричной форме, а также обогатить ее дополнительными оттенками значения. Существует несколько способов выражения косвенного запрета с учетом коммуникативно-прагматической ситуации. 
1. выражение запрета через побуждение к такому действию, которое не совместимо с данным.

- Оставьте эту женщину! - бешеным голосом прохрипел Пьер, схватывая длинного, сутуловатого солдата за плечи и отбрасывая его (Л.Н. Толстой) - побуждение к действию, которое не совместимо с запрещаемым действием, выражено в словоформе «оставьте» и имеет значение «не беспокойте», «не смейте беспокоить», «не рекомендую беспокоить».

Мама научила меня преодолевать невозможное: «3акрой pom и ешь суп» (Журнал «Сварка и резка») - очевидно, что второй пример построен на игре слов, но, если отвлечься от этого и принять значение слов «закрой poт» не буквально, а в значении «перестань болтать», то данное высказывание является ярким примером выражения косвенного запрета через побуждение к другому (некаузируемому) действию. В данном случае важен не столько запрет, а важно само побуждение к осуществлению другого действия, возможного только при соблюдении запрета.

2. Выражение косвенного запрета через отрицательную оценку запрещаемого действия. Данный случай выражения запрета связан с желанием адресанта объяснить причину, по которой действие запрещается. Отрицательное отношение адресанта связано с рядом причин: действие может отрицательно влиять на положение человека в обществе, на его отношение с другими людьми, запрет к осуществлению действия может быть связан с опасностью совершения действия.

Пьер, выйдя в коридор, с жалостью и отвращением смотрел на этого полусумасшедшего старика. Макар Алексеич, морщась от усилий, удерживал пистолет и кричал хриплым голосом, видимо себе воображая чтото торжественное.

- Это нехорошо, сударь... (слова Пьера, обращенные к старику) (Л. Толстой)- осуждение поступка человека представлено в форме запрета действия. Из этой негативной оценки вытекает вполне определенный смысл, который может быть представлен эксплицитно «не смей так nоступать».

3. Косвенная форма запрета используется при его выражении через положительную оценку действия, которое не совместимо с запрещаемым действием. В этом случае важно учитывать не просто желание запретить адресату совершать действие ради другого, а стремление объяснить причину, по которой другое действие является предпочтительнее запрещаемого действия. Запрет связан с идеей одобрения действия, которое еще не осуществилось (идея пойти вперед), но было бы осуществлено при определенных условиях (невозможность двигаться в других направлениях), а именно при недо- пущении запрещаемого действия.

4. Косвенный запрет может осуществляться через вопрос, связанный с неодобрением, например:

Затем он повернулся к врачу, протянул ему руку, сухо сказал «до свидания» и собрался уходить.

- Помилуйте, куда же вы хотите идти? - заговорил врач, вглядываясь в глаза Ивана, - глубокой ночью, в белье... Вы плохо чувствуете себя, останьтесь у нас! ( $М$. Булгаков) - косвенный запрет выражен в форме запроса информации с помощью вопросительного слова «куда», этот запрет может быть спроецирован на эксплицитную форму воплощения с помощью глагола в форме повелительного наклонения с отрицательной частицей «не» (не ходи!). Вопрос подкреплен разумными доводами не совершать действия и императивом глагола «остаться». Косвенно представленная идея запрета в данном случае могла быть выражена и эксплицитно: не ходите никуда.

Существуют различные способы выражения прямого и косвенного запрета, и употребление каждого из них является прагматически обусловленным. Прямой запрет употребляется при желании максимально доступно выразить запрет, косвенный - при желании сформулировать запрет мягче.

Таким образом, можно рассматривать РА запрещения как одно из средств манипулирования, как вид речевого воздействия на собеседника. Выбор языковых средств для выражения прямого или косвенного воздействия служит основанием для достижения / недостижения цели, которую преследует говорящий в процессе коммуникации. Языковые средства выражения запрета обусловлены характером коммуникации. Средства выражения в официальной и неофициальной сфере общения будут разниться, как и в устной и письменной речи. Так, например, в устной неофициальной речи преобладают императивы с частицей отрицания или без нее, междометия и т.п., в официальной - сочетания императива, отрицательной частицы и инфинитива глагола действия, безличные конструкции и т.п. Выявленные средства и способы репрезентации запрета не являются полным перечнем средств выражения, но это наиболее часто встречающиеся языковые средства выражения запрета в русской речи. Изучение побудительных речевых актов в прагмалингвистике необходимо. Вследствие частотности употребления РА запрета в процессе коммуникации сложились определенные стереотипы поведения в ситуации запрещения, но, несмотря на это, часто случаются коммуникативные неудачи, при которых общение становится конфликтным. Вследствие этого необходимо дальнейшее изучения коммуникативных ситуаций запрещения, чтобы выработать правила поведения, нацеленные на успешное речевое взаимодействие коммуникантов. 


\section{ЛИТЕРАТУРА}

1. Апресян Ю.Д. Избранные труды, том ІІ. Интегральное описание языка и системная лексикография. - М.: «Языки русской культуры», 1995. - 767 с.

2. Арутюнова Н.Д. Язык и мир человека. - М.: «Языки русской культуры», 1999. - 896 с.

3. Беляева Е.И. Грамматика и прагматика побуждения: английский язык: монография. - Воронеж: Издательство Воронежского гос. университета, 1992. 184 c.

4. Большакова Т.М. Состав и функционально-прагматические особенности лексико-семантического поля глаголов запрещения / Т.М.Большакова. - СПБ.: ЭКСМ0, 2003. $-488 \mathrm{C}$

5. Сарайкина 0.В. Репертуар языковых средств выражения семантики запрета /автореферат на соиск.уч.степени канд.филолог. наук - ПетропавловскКамчатский: КамГУ, $2007-24$ с.

6. Саранцацрал Ц. Речевые акты побуждения, их типы и способы выражения в русском языке. - М., 1993. - 48 с.

7. Сусов И.П. Лингвистическая прагматика / под ред. Карабан В.И. - Винница: Новая книга, 2009 г. - 272 с.

8. Филатова Е.А. Побуждение и императив: способы выражения побуждения по-русски. - М.: Издательство МНУ, 2002. - 76 с.

9. Формановская Н.И. Речевое взаимодействие: коммуникация и прагматика. - М.: ИКАР, 2007. - 480 с.

(c) Россолова Оксана Анатольевна (oksross@mail.ru).

Журнал «Современная наука: актуальные проблемы теории и практики»

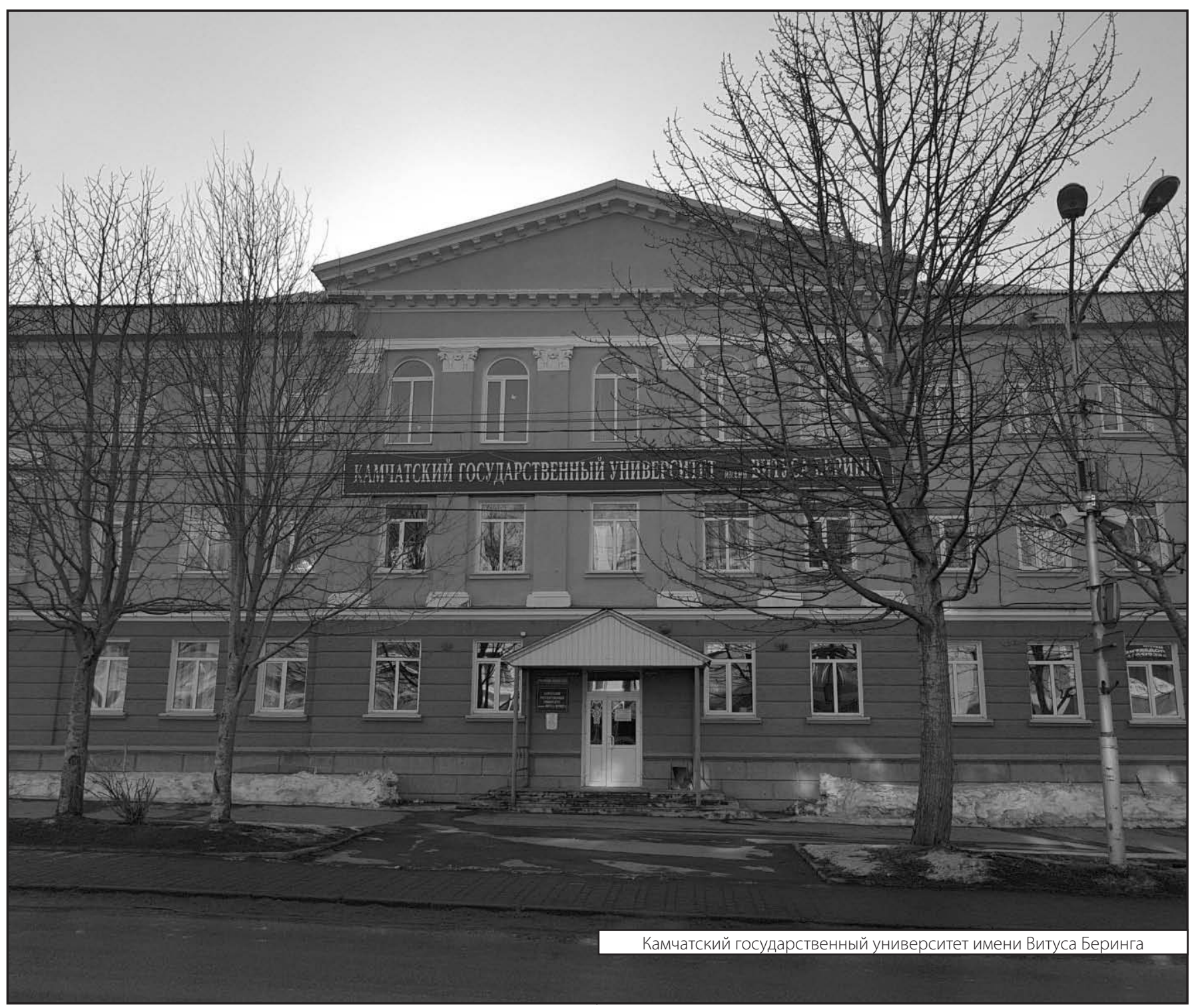

